\title{
Impact of Fibromyalgia on Female Infertility
}

\author{
Maïmouna Coura Koné1, Nabé Alphonse Kambiré2, Yapi Ahoua ${ }^{3}$ \\ ${ }^{1}$ Biology and Health Laboratory, Biology of Reproduction and Development Unit, Biosciences UFR, Félix Houphoüet-Boigny \\ University, Abidjan, Ivory Coast \\ ${ }^{2}$ Department of Psychology, Human and Social Sciences UFR, Félix Houphoüet-Boigny University, Abidjan, Ivory Coast \\ ${ }^{3}$ Biology and Health Laboratory, Biosciences UFR, Félix Houphouët-Boigny University, Abidjan, Ivory Coast \\ Email:kone.coura@ufhb.edu.ci, kambirenabe@gmail.com, yapi.ahoua@ufhb.edu.ci
}

How to cite this paper: Koné, M.C., Kambiré, N.A. and Ahoua, Y. (2021) Impact of Fibromyalgia on Female Infertility. Open Journal of Epidemiology, 11, 457-472. https://doi.org/10.4236/ojepi.2021.114037

Received: August 27, 2021

Accepted: November 13, 2021

Published: November 16, 2021

Copyright ( 2021 by author(s) and Scientific Research Publishing Inc. This work is licensed under the Creative Commons Attribution International License (CC BY 4.0).

http://creativecommons.org/licenses/by/4.0/

\section{(c) (i) Open Access}

\begin{abstract}
Fibromyalgia is a chronic, widespread musculoskeletal pain and polyalgic syndrome, evolving for more than three months. Research on its consequences on fertility is therefore relevant to explore. The aim of this study is to highlight the relationship between fibromyalgia and some women's diseases that induced infertility. The results showed that fibromyalgia is more common in $92.9 \%$ of patients wishing to procreate and $64.8 \%$ of patients with gynecological disorders. $70.7 \%$ of patients with menstrual disorder have fibromyalgia and $76.5 \%$ of fibromyalgia patients have myomas. Among ovarian pathologies, $76.5 \%$ of women with ovarian dystrophy have fibromyalgia. Fibromyalgia is also very prevalent in women with miscarriage (55.9\%) and stillbirth history (90.1\%). For all studied situations, a highly significant difference was observed $(\mathrm{p}<0.000)$. All these data suggest that fibromyalgia is related to different situations that can induce infertility in women.
\end{abstract}

\section{Keywords}

Fibromyalgia, Gynecological Diseases, Stillbirth, Miscarrige, Infertility

\section{Introduction}

Fibromyalgia is a chronic, widespread musculoskeletal pain and polyalgic syndrome [1], evolving for more than three months. Fibromyalgia was found on palpation and increased with exertion. These pains often predominate in the axial and proximal regions of the limbs and no anatomical lesions are found [2]. In addition to pain, fibromyalgia is associated with other disorders such as asthenia, sleep disturbances, mood disturbances, anxiety depression, also considered to be symptoms [3]-[8]. This syndrome sets in overtime, with fluctuations in intensity and repercussions on family and professional life. These periods are sometimes linked 
to stress and life events [9]. Fibromyalgia is accompanied by digestive disorders, in particular irritable bowel syndrome [10] [11], pelvic pain, genitourinary disorders, memory disorders, anxiety and depression [12] [13] and arthrosis [13]. These different co-morbidities most often seem to be consecutive to fibromyalgia [14].

Fibromyalgia affects between $0.2 \%$ and $6.6 \%$ [15] but it seems less common in Asia and sub-Saharan Africa [16]. The average age of onset is around 25 to 40 years old. Women between 40 and 50 years old (between pre-menopause and menopause) are most affected by fibromyalgia [13] [17]. However, some young people, adults, adolescents or children may have fibromyalgia [14]. Chronic physical pain is an unpleasant sensory and emotional experience that is increasingly present in individuals with various illnesses. Indeed, this chronicity of physical pain is present in $11.5 \%$ to $52.2 \%$ of the adult world population [18]. Present studies show a very high prevalence of fibromyalgia in women in the general population [15] [19]. The female predominance of fibromyalgia is closely related to sexual hormones [20]. In the particular case of women, the highest pain thresholds were found during folliculogenesis [21]. Symptoms of fibromyalgia vary according to the menstrual cycle [22]. They seem less severe in men [23].

Fibromyalgia's causes remain unclear. The Cerebrospinal Fluid (CSF) proteomics analyses in fibromyalgia patients revealed dysregulation of proteins involved in lipoprotein lipase activity, inflammatory signaling, energy metabolism, neuropeptide signaling, proteins related to pain [24] [25]. But it appears that the disease involves several mechanisms. The imbalance of the serotonergic system seems to be the main etiological factor of this pathology. Other neurotransmitters such as P substance, N-methyl-D-aspartate, noradrenalin [26] [27] [28] [29] are implicated. Dysfunctions of the Hypothalamic-Pituitary-Adrenal (HPA) axis, as well as sexual hormones, are involved [30]. HPA is usually activated in the stress response. One of its molecular messengers, CRH (Corticotropin-Releasing Hormone) stimulates the secretion of ACTH which promotes the secretion of cortisol [31]. The synthesis of this hypothalamic $\mathrm{CRH}$ involved in reproduction, varies with age and reproductive function [32]. CRH can be of peripheral origin, detected in the ovary, myometrium, endometrium and placenta. The role of this CRH in reproduction has also been described [33] [34] [35] [36]. In the case of fibromyalgia, there is a hyperactivation of the HPA leading to several consequences at the physiological level. One of the physiological functions affected is reproduction. Based on a study relating to endocrine profile of fibromyalgia patients [37], it appears that fluctuations in CRH secretion and in particular the increase would determine several symptoms observed in fibromyalgia and would also affect the functioning of other hormonal axes. The Hypothalamic-Pituitary-Gonadotropic (HPG) axis controls reproduction through Gonadotropin-Releasing Hormone (GnRH) which regulates the synthesis of FSH and LH hormones as well as sexual hormones, is particularly disturbed. There is an interaction between the HPA and the HPG which is bidirectional. CRH inhibits the secretion of GnRH. The 
secretion of CRH can be directly regulated by estrogens [36] [38].

The regulation of HPG by HPA is clearly established. It can easily be assumed that the dysfunction of the HPA, though weak, as observed in fibromyalgia, could have negative consequences on reproduction and by extension on fertility. Research on its consequences on fertility and in particular demonstration of a link between fibromyalgia and infertility are therefore relevant to explore. To date, no epidemiological study describes cases of patients diagnosed with fibromyalgia and presenting infertility of various origins.

The general objective of this work was to highlight the relationship between fibromyalgia and different cases of infertility. Particularly, we looked for fibromyalgia in patients in the various units of the gynecology department of the General Hospital of Grand-Bassam. Then we evaluated the strength of the link between fibromyalgia and the different types of infertility observed.

\section{Materials and Methods}

\subsection{Material}

An epidemiological study was carried out with 264 patients at the General Hospital of Grand-Bassam. This transversal study took place in the gynecology department women coming for consultations in the gynecological sub-services were included regardless of their age. We have considered only the age at the moment of the investigation. We don't However, women with sexually transmitted infections consulting for rape and abortion cases were excluded from the study.

\subsection{Methods}

\subsubsection{Investigation}

- An investigation sheet was formulated for carrying out the study. This sheet included: the identity of the patient; her medical and surgical history, the gynecological pathologies from which she suffers;

- A Fibromyalgia Impact Questionnaire (FIQ): this questionnaire is used to measure the evolution of fibromyalgia. It includes 10 questions with for each one a choice between 2 answers: "yes" or "no". The degree to which fibromyalgia is affected, as well as the discrimination between fibromyalgia (Fib) and non-fibromyalgia (non-Fib) patients depends on the frequencies of "yes" responses. Thus, fibromyalgia patients have at least 5 "yes" in their response and we consider severe fibromyalgia involvement if the patients have at least 7 "yes" in 10;

- Searching for painful points according to the American College of Rheumatology (ACR) method [6]. This method consists of looking for at least 11 pain points out of 18 defined points. In practice, it corresponds to a palpation which makes it possible to whiten the nail.

\subsubsection{Statistical Analyzes}

The data previously collected on the survey forms were entered and processed 
using IBM SPSS version 20 software. The variables are expressed in frequency and in percentage. The comparisons of the variables between the diagnosis of fibromyalgia and the different situations encountered in the gynecology department were carried out by Pearson's chi-square test according to the theoretical numbers. A p-value $<0.05$ was considered statistically significant. A p-value $<0.01$ was considered statistically very significant and a $\mathrm{p}$-value $=0.000$ was considered highly significant.

\section{Results}

\subsection{Prevalence of Fibromyalgia in the Gynecological Departments of the General Hospital of Grand-Bassam}

264 patients were registered in the gynecology department of the Grand-Bassam general hospital during the study. 37\% of women (98/264) were diagnosed positive for fibromyalgia (Figure 1). We interviewed patients aged between 13 and 65 years old. There is a high proportion of women with fibromyalgia (55\%) for the age group between 21 - 30 years old compared to others age groups (Figure 2).

\subsection{Relationship between Fibromyalgia and the Situations Encountered in the Gynecology Department}

To establish a relationship between fibromyalgia and the various situations encountered in the gynecology department, we interviewed patients with various

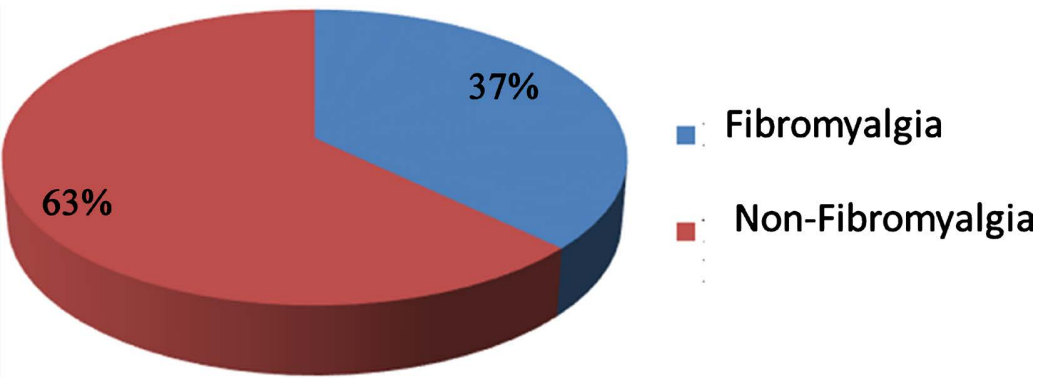

Figure 1. Distribution of patients in the study according to fibromyalgia. $37 \%$ of patients in the gynecology department diagnosed positive for fibromyalgia.

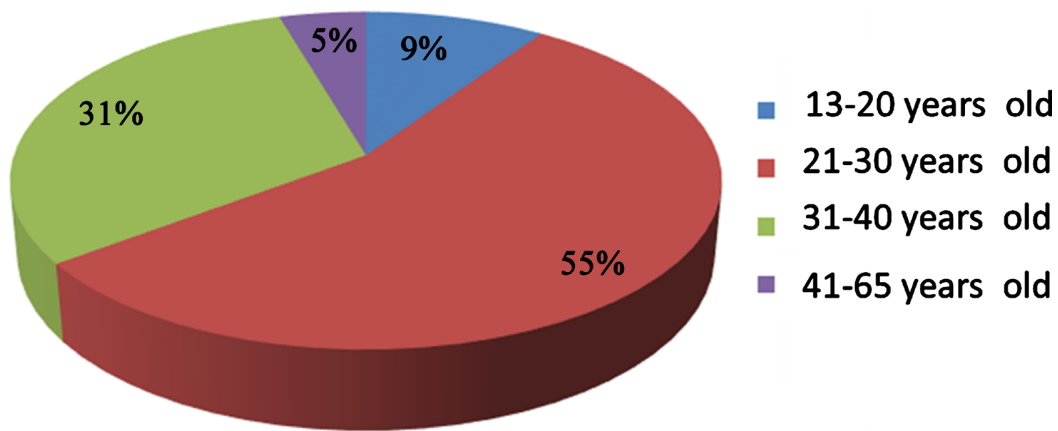

Figure 2. Distribution of fibromyalgia patients by age. High rate of fibromyalgia women (55\%) aged between $21-30$ years. 
pathologies: patients with gynecological diseases, patients wishing to procreate, pregnant patients and patients who have already given birth. We found a prevalence of fibromyalgia in all of the patients interviewed but at variable rates (Table 1). In fact, fibromyalgia is mainly observed in women wishing to procreate $(13 / 14$ patients; 92.9\%) and women with some gynecological pathologies (46/71 patients; $64.8 \%)$. In contrast, the frequency of fibromyalgia was lower in pregnant patients $(13 / 68 ; 19.1 \%)$ and those who gave birth $(26 / 111 ; 23.4 \%)$. These data suggest that infertility as well as some gynecological pathologies observed in the patients would be consecutive to fibromyalgia.

\subsection{Link between Fibromyalgia and Gynecological Pathologies}

To specifically establish a link between fibromyalgia and gynecological pathologies, we looked for fibromyalgia in patients presenting menstrual cycle disorders, pathologies of the uterus and pathologies of the ovary.

\subsubsection{Menstrual Cycle Disorders}

99 patients with menstrual cycle disorders were listed (Table 2). The proportion of patients with fibromyalgia (70/99, 70.7\%) among these patients is higher than that of women without fibromyalgia $(29 / 99,17 \%)$. The difference is highly significant for $\mathrm{p}=0.000$. These results suggest a link between fibromyalgia and the

Table 1. Relationship between fibromyalgia and the situations encountered in the gynecology department of the General Hospital of Grand-Bassam. Fibromyalgia is more common in $92.9 \%$ of patients wishing to procreate and $64.8 \%$ of patients with gynecological disorders.

\begin{tabular}{cccc}
\hline & \multicolumn{2}{c}{ Diagnosis of fibromyalgia [n (\%)] } & \multirow{2}{*}{ Total } \\
\cline { 2 - 3 } & Yes & No & \\
\hline Patients with gynecological conditions & $46(64.8 \%)$ & $25(35.2 \%)$ & 71 \\
Pregnancy monitoring & $13(19.1 \%)$ & $55(80.9 \%)$ & 68 \\
Motherhood desire & $13(92.9 \%)$ & $1(7.1 \%)$ & 14 \\
Birth & $26(23.4 \%)$ & $85(76.6 \%)$ & 111 \\
Total & $98(37 \%)$ & $166(63 \%)$ & 264 \\
\hline
\end{tabular}

Table 2. Link between fibromyalgia and menstrual cycle disorder. 70.7\% of patients with menstrual disorder have fibromyalgia. Highly significant Pearson chi-square test for $\mathrm{p}$-value $=0.000$.

\begin{tabular}{|c|c|c|c|c|c|}
\hline & \multicolumn{2}{|c|}{$\begin{array}{c}\text { Diagnosis of fibromyalgia } \\
\mathrm{n}(\%)\end{array}$} & \multirow[t]{2}{*}{$X^{2}$} & \multirow{2}{*}{$P$-value } & \multirow{2}{*}{ Total } \\
\hline & Yes & No & & & \\
\hline Menstrual cycle disorder & $70(70.7 \%)$ & $29(29.3 \%)$ & 76.549 & 0.000 & 99 \\
\hline No menstrual cycle disorder & $28(17.0 \%)$ & $137(83.0 \%)$ & & & 165 \\
\hline \multicolumn{3}{|c|}{ Total } & & & 264 \\
\hline
\end{tabular}


onset of menstrual disturbances.

\subsubsection{Uterus Pathologies}

Overall, 20 patients with pathologies of the uterus were recorded (Table 3). These are mainly myomas, fibromas and polyps. For each of these pathologies, fibromyalgia is observed in the majority of patients questioned. Most cases of myomas are detected in female patients (17/20). Of the 17 patients with myomas, a large proportion $(13 / 17,76.5 \%)$ were diagnosed with fibromyalgia. For fibromas (7 cases) and polyps ( 1 case), very few patients could be questioned, however with high proportions of fibromyalgia patients. Indeed, in patients suffering from fibromas $(6 / 7,85.7 \%)$ and patients with polyps $(1 / 1,100 \%)$ are fibromyalgic. The differences observed between the proportions of fibromyalgia and non-fibromyalgia patients relating to pathologies are highly significant for $\mathrm{p}=0.000$. These data suggest a link between fibromyalgia and some pathologies of uterus, including myomas, fibromas and polyps.

\subsubsection{Ovary Pathologies}

18 cases of ovarian pathologies were listed (Table 4). These pathologies are dystrophy and cysts with a high proportion of fibromyalgia patients in each case. In fact, among the patients with ovarian dystrophy, 11/14 patients were diagnosed

Table 3. Link between fibromyalgia and pathologies of uterus. The majority of patients with myomas with $76.5 \%$ of fibromyalgia patients. Few cases of fibroma and polyp with however high proportions of fibromyalgia patients ( $86.7 \%$ and $100 \%$ respectively). Highly significant Pearson chi-square test for a p-value $=0.000$.

\begin{tabular}{cccccc} 
& \multicolumn{2}{c}{ Diagnosis of fibromyalgia [n (\%) } & \multirow{2}{*}{$\boldsymbol{X}^{2}$} & P-value & Total \\
\cline { 2 - 3 } & Yes & No & & & \\
\hline Myoma & $13(76.5 \%)$ & $4(23.5 \%)$ & 22.112 & 0.000 & 17 \\
Fibroma & $6(85.7 \%)$ & $1(14.3 \%)$ & & & 7 \\
Polyp & $1(100 \%)$ & 0 & & 1 \\
No pathology & $78(32.6)$ & $161(67.4 \%)$ & & 239 \\
& Total & & & 264 \\
\hline
\end{tabular}

Table 4. Link between fibromyalgia and ovary pathologies. Patients with dystrophy are predominantly represented with a high frequency of fibromyalgia patients $(11 / 14 ; 76.5 \%)$. Few cases of cysts with however high proportions of fibromyalgia patients $(4 / 4 ; 100 \%)$. Very significant Pearson chi-square test for $\mathrm{p}$-value $=0.01$.

\begin{tabular}{cccccc}
\hline & \multicolumn{2}{c}{ Diagnosis of fibromyalgia [n (\%)] } & \multirow{2}{*}{$X^{2}$} & P-value & Total \\
\cline { 2 - 3 } & Yes & No & & & \\
\hline Ovarian dystrophy & $11(78.6 \%)$ & $3(21.4 \%)$ & 20.176 & 0.01 & 14 \\
Ovarian cyst & $4(100 \%)$ & 0 & & 4 \\
No pathology & $83(33.73 \%)$ & $163(66.26 \%)$ & & 246 \\
& Total & & & 264 \\
\hline
\end{tabular}


with fibromyalgia with a rate of $78.6 \%$. In the case of ovarian cysts, fibromyalgia was detected in the 4 patients questioned, corresponding to a rate of $100 \%$. For each pathology, the rate of fibromyalgia patients is very significantly different from the rate of non-fibromyalgia patients for $\mathrm{p}=0.01$. These results suggest a link between ovarian pathologies and fibromyalgia.

In sum, these data show a relationship between fibromyalgia and some gynecological pathology associated with infertility.

\subsection{Link between Fibromyalgia and Patient Medical History: Miscarriage and Stillbirth Histories Cases}

Then, we wanted to establish the link between fibromyalgia and the inability to carry a pregnancy to term. We considered that it is impossible to carry a pregnancy to term when the patient had a history of recurrent miscarriages and stillbirths. We therefore looked for fibromyalgia specifically in these patients.

\subsubsection{History of Miscarriage Cases}

A total of 68 patients with a history of miscarriage were recorded. 38/68 patients were diagnosed with fibromyalgia with a rate of $55.9 \%$ (38/68) (Table 5). The difference between fibromyalgia and non-fibromyalgia patients $(44.1 \%)$ is highly significant $(p=0.000)$. The results suggested a link between fibromyalgia and a history of miscarriage.

\subsubsection{History of Stillbirth}

Eleven patients with a history of stillbirth were also recorded (Table 6). Among these patients, 10 were declared fibromyalgia, corresponding to a rate of $90.9 \%$.

Table 5. Link between fibromyalgia and the patient's history of miscarriage. 55.9\% of patients with a history of miscarriage have fibromyalgia. Highly significant Pearson chi-square test for $\mathrm{p}=0.000$.

\begin{tabular}{|c|c|c|c|c|c|}
\hline & \multicolumn{2}{|c|}{ Diagnosis of fibromyalgia [n (\%)] } & \multirow{2}{*}{$X^{2}$} & \multirow{2}{*}{$\mathrm{P}$-value } & \multirow{2}{*}{ Total } \\
\hline & Yes & No & & & \\
\hline Miscarriage & $38(55.9 \%)$ & $30(44.1 \%)$ & 13.812 & 0.000 & 68 \\
\hline \multirow[t]{2}{*}{ No Miscarriage } & $60(30.6 \%)$ & $136(69.4 \%)$ & & & 196 \\
\hline & Total & & & & 264 \\
\hline
\end{tabular}

Table 6. Link between fibromyalgia and history of stillbirth. $90.9 \%$ of patients with a history of stillbirth have fibromyalgia. Highly significant Pearson chi-square test for $\mathrm{p}=$ 0.000 .

\begin{tabular}{cccccc}
\hline & \multicolumn{2}{c}{ Diagnosis of fibromyalgia [n (\%)] } & \multirow{2}{*}{$X^{2}$} & P-value & Total \\
\cline { 2 - 5 } & Yes & No & & & \\
\hline Stillborn & $10(90.9 \%)$ & $1(9.1 \%)$ & 14.227 & 0.000 & 11 \\
No stillborn & $88(34.8)$ & $165(65.2 \%)$ & & & 253 \\
& Total & & & 264 \\
\hline
\end{tabular}


The difference between the rate of fibromyalgia and non-fibromyalgia patients $(34.8 \%)$ is highly significant $(\mathrm{p}=0.000)$. These data suggest that there is a link between fibromyalgia and a history of stillbirth.

\section{Discussion}

This study was the first epidemiological survey carried out in Ivory Coast whose objective was to establish a relationship between fibromyalgia and infertility in women. We looked for fibromyalgia in 264 patients in the gynecology department of the Grand-Bassam general hospital. In this department, we met different cases including patients who have given birth, patients consulting for pregnancy monitoring, patients consulting following a desire for maternity, patients suffering from gynecological pathologies.

The survey showed that 98/264 patients have fibromyalgia. But this proportion is not significantly different from that of women without fibromyalgia (166/264). $55 \%$ of women aged ranged between 31 and 41 years old have fibromyalgia. This is in discordance with We particularly observed fibromyalgia in patients consulting following a desire for maternity, patients suffering from gynecological pathologies. The link between these 2 cases is infertility which could be a consequence associated to these situations. These data suggest a relationship between fibromyalgia and these pathologies and, by extrapolation, infertility. They are also in agreement with the data of [39] that showed a high prevalence of gynecological, endocrine and autoimmune diseases in women with fibromyalgia. The dysfunction of the hypothalamic-pituitary axis is generally associated to fibromyalgia as well as to gynecological and endocrine pathologies [40], thus suggesting a comorbidity with fibromyalgia.

In particular, we observed fibromyalgia mainly in women showing a desire for motherhood (92.9\%) and women suffering from gynecological conditions (64.8\%), thus suggesting a link between fibromyalgia and these different pathological conditions. In both situations, these women present either an unsuspected infertility or a proven infertility associated with diagnosis of fibromyalgia. The desire for childbirth could be compromised for a woman with fibromyalgia because of negative consequences on fertility. Indeed, there is a proven risk of infertility following fibromyalgia because the dysfunction of the hypothalamic-pituitary axis also influences the regulation of hormones involved in woman's reproduction. The function of the hypothalamic-pituitary-adrenal axis in fibromyalgia as well as its interaction with the hypothalamic-pituitary-gonadotropic axis controlling the reproductive system [37] [41] [32] supports this idea. Indeed, GnRH acts on pituitary gland to produce FSH and LH which will stimulate production of estrogens and progesterone by gonads. These hormones are involved in the regulation of sexual cycle, ovulation, implantation, gestation, parturition and lactation. However, secretion of GnRH can be inhibited by HPA. This inhibition of GnRH blocks the reproductive system according to two mechanisms. The first involves an inhibitory action of $\mathrm{CRH}$ on $\mathrm{GnRH}$ neurons of arcuate and preoptic nuclei of preoptic 
medial area. There is also a peripheral CRH of non-hypothalamic origin, also implicated in reproduction and detected in ovaries, myometrium, endometrium and placenta [33] [34] [36] of which fluctuations influence various functions of these tissues. The second mechanism concerns glucocorticoids which also inhibit GnRH neurons and will affect the secretion of LH and steroids [36]. These data were in accordance with the idea that fibromyalgia disturbs reproductive function and could lead to infertility in women.

Most of women with gynecological pathologies (64.8\%) have been tested positive for fibromyalgia. These data suggest a relationship between the manifestation of some gynecological pathologies and the fibromyalgia state. In general, women are exposed to many hormonal variations caused by diet, lifestyle, disease and the use of drugs throughout their lives. These variations, in particular hyperestrogenism can lead to premenstrual syndromes, endometriosis, uterine fibroids, menstrual disturbances, infertility and breast cancer [42]. Hyperestrogenism could explain these disorders. Indeed, these gynecological pathologies are most often related to pituitary-ovarian hormonal dysfunction. We particularly observed that proportion of women suffering from menstrual disturbances and diagnosed with fibromyalgia $(70 / 99 ; 70.7 \%)$ is significantly higher than those of non-fibromyalgia patients. There is therefore a link between fibromyalgia and menstrual disturbances. Menstrual disturbances can occur as a result of dysfunction appearing at different stages of menstrual cycle. The combined action of gonadotropins and sex steroids is essential for successful completion of each of these steps. Other hypotheses could explain menstrual disturbances observed in fibromyalgia patients. One of them could involve the relationship between regularity of ovulatory cycle and sleep disturbances (a symptom associated with fibromyalgia) also involving leptin. Sleep disturbances directly related to estrogens levels [43] disrupt the ovary cycle and disrupt adequate leptin production. However, leptin is involved in folliculogenesis by indirectly regulating the levels of LH and FSH. Thus, in the event of sleep disturbances, ovulation is compromised, thereby leading to menstrual disturbances [44] [45] [46]. The other hypothesis is related to peripheral CRH detected in the ovary and endometrium. Ovarian CRH is believed to participate in communication between egg and cells of the cumulus oophorus. It has also been suggested that this CRH could block the production of estrogens and progesterone [33] [47] [48]. In addition, CRH is produced by endothelial cells in endometrium throughout a normal menstrual cycle [34]. Decreasing in CRH production below the normal secretion level could disturb menstrual cycle. Overexpression of CRH could be also considered in this situation.

Several types of uterin pathologies have been detected in patients with a large majority of myoma cases. The proportion of women who are affected and diagnosed with fibromyalgia (76.5\%) was significantly higher than that of women without fibromyalgia. The same observation was also made in the case of fibroids $(87.5 \%)$ and polyps (100\%). Uterin leiomyoma (or myoma or fibroma) is the most common benign tumor in women of childbearing age (20 - 30 years), and represents the first indication for hysterectomy in pre-menopausal women [49]. 
Black women would develop more fibroids at a younger age than white women [50]. There is family predisposition and factors significantly associated with the growth of fibroids, which are: obesity, age of first menstruation less than 12 years, nulliparity and infertility [51]. Like fibroids and myomas, polyps are benign tumors of the uterus whose onset and persistence depend on hormonal fluctuations. In these conditions, the hypotheses of hyperandrogenism, the presence of $\mathrm{CRH}$ in the myometrium and endometrium as well as its involvement in the regulation of estrogens and progesterone remain possible [32]. While the role of hormones such as estrogens and progesterone is undeniable, their precise modes of action in the case of fibromyalgia remain unclear [52].

For patients with ovarian pathologies, we mainly detected cases of ovarian dystrophy (polycystic ovarian syndrome) and ovarian cyst. 78\% of patients with ovarian dystrophy and $100 \%$ of patients with cysts have been diagnosed with fibromyalgia. The difference observed between fibromyalgia and non-fribromyalgia patients is very significant, suggesting a strong relationship between fibromyalgia and these ovarian's pathologies. Ovarian dystrophy is a pathology linked to an endocrine disorder. It is characterized, among other things, by chronic anovulation, hyperandrogenism and infertility [53] [54]. It can be caused by several factors (ovarian and central). It is associated with the disruption of the secretion of gonadotropins (abnormally high level of LH outside the normal pre-ovulatory peak), the excessive secretion of androgen (hyperandrogenism) by the ovary which blocks follicular maturation and acyclic production of estrogens. In fibromyalgia, the hyperactivity of the hypothalamic-pituitary-adrenal axis is believed to be involved in the manifestation of dystrophy. The relationship observed between fibromyalgia and ovarian dystrophy in our study is consistent with this idea. Our results could therefore be explained by the intervention of the hypothalamic-pituitary-adrenal axis [55] and in particular the intense activity of this axis. In fact, under these conditions, there is an increase in the production of cortisol and androgens by the ovary.

Unlike dystrophy where immature follicles accumulate, ovarian cyst is a swelling containing fluid and developing on the ovaries. $5 \%$ to $7 \%$ of women have at least developed an ovarian cyst in their lifetime. They are either functional (pre-ovulatory or anovulatory follicle and cystic corpus luteum) and transient influenced by hormonal secretions from the cycle, or organic. Several factors can be responsible for the development of ovarian cysts. One of the main factors is hormonal disorders (female hormones and high male hormone levels). It is well known that gynecological and endocrine pathologies are commonly observed in fibromyalgia patients [39]. The diagnosis of fibromyalgia in patients with ovarian cysts is therefore not surprising. Knowing the implication of hormonal sections during the menstrual cycle in the appearance of some cysts, we can hypothesize the hormonal dysfunction observed in the case of fibromyalgia to explain their manifestation. However, the precise mechanism remains to be determined.

Our data suggest a highly significant link between fibromyalgia and histories of miscarriage. Indeed, $55.9 \%$ of patients with a history of miscarriages have fi- 
bromyalgia. This relationship could be explained by the failure of the hypothalamic-pituitary axis observed both during pregnancy and in fibromyalgia. At ovulation, follicular cells luteinize under the action of LH. At the same time, corpus luteum begins to synthesize large amounts of estrogens and progesterone to prepare the uterin lace and allow implantation. This production continues to increase during gestation because estrogens help stimulate the growth of uterin muscle mass and its vascularization while progesterone maintains uterin silence by blocking contraction [56]. Hormonal imbalance due to a failure of hypothalamic-pituitary axis would lead to a drop in hormones, lifting the uterin silence and leading to spontaneous abortions. Fibromyalgia causes repetitive painful muscle contractions that weaken the uterine muscle. Uterine weakening could also cause a spontaneous abortion. Another hypothesis concerns peripheral CRH detected in the endometrium. The fetus is considered a semi-allogeneic transplant by the mother's immune system. Its protection is ensured by $\mathrm{CRH}$ that involved in implantation (considered an aseptic inflammatory process) and anti-rejection of the fetus by the maternal body. Pregnancy is a special condition causing suffering in the mother. When future mother is diagnosed with fibromyalgia, she also feels muscle pain in this condition where the hormonal system is disturbed, the central nervous system could send signals to reject the fetus in order to alleviate the suffering of mother. Based on these data, it is possible that dysfunction in regulation of endometrial CRH could lead to spontaneous abortion [34] [57]. Taken together, all these situations could lead to spontaneous abortion.

Stillbirth is when a baby isborn without any sign of life. We find that $90.9 \%$ of patients with a history of stillbirth have fibromyalgia with a highly significant difference compared compared to women with no history of stillbirth. The mechanism is difficult to identify. Certainly, CRH appears to play a crucial role in the development of the fetus and the survival of the newborn, but it does not appear to be the singlefactor. Several hypotheses concerning the involvement of maternal HPA, placental CRH and the intervention of fetal HPA could explain this relationship between a history of stillbirth and fibromyalgia [32]. Thus, Mclean et al. [58] considers maternal HPA as a biological "clock" that sets early during pregnancy and in which placental CRH determines the duration of pregnancy. The hormonal dysfunction observed in the case of fibromyalgia could cause deregulation responsible for complications in utero or premature deliveries that do not allow the survival of the fetus.

\section{Conclusion and Perspectives}

All of the data presented in this preliminary epidemiological study allow us to establish a relationship between fibromyalgia and some gynecological pathologies leading to infertility in women. For all pathological situations encountered, the proportion of fibromyalgia women is significantly higher than that of non-fibromyalgia women. Thus there is a relationship between fibromyalgia and some gynecological affections leading to infertility. It seems that hormonal dis- 
orders could be the main factor involved. HPA activity related to fibromyalgia and fluctuations of peripheral CRH could be involved in reproductive dysfunction observed. However, the diversity of the factors involved in the manifestation of fibromyalgia as well as the mechanisms generating these consequences on reproduction raise many relevant questions to be explored. Therefore, it would be appropriate to continue this epidemiological study on a larger workforce and try to understand the precise mechanisms involved in the manifestation of the gynecological pathologies observed in fibromyalgia patients. It would first be necessary to determine the precise causes of these pathologies affecting reproduction. Secondly, it would be a good idea to have $\mathrm{CRH}$, ACTH, cortisol, gonadotropins and sex steroids hormonal assays in parallel in these patients. So far, we have considered that the gynecological pathologies and the difficulties in giving birth were consecutive to fibromyalgia.

\section{Conflicts of Interest}

The authors declare no conflicts of interest regarding the publication of this paper.

\section{References}

[1] Bair, M.J. and Krebs, E.E. (2020) Fibromyalgia. Annals of Internal Medicine, 172, ITC33-ITC48.

[2] Khan, M.F. (2009) Syndrome Fibromyalgique. EMC traité de medecine AKOS, 12, 125-126.

[3] Moldofsky, H. (2002) Management of Sleep Discorders in Fibromyalgia. Rheumatic Disease Clinics of North America, 28, 353-365.

[4] Buskila, D. and Sarzi-Puttini, P. (2006) Biology and Therapy of Fibromyalgia. Arthritis Research \& Therapy, 8, Article No. 218. https://doi.org/10.1186/ar2005

[5] Osorio, C.D., Gallinaro, A.L., Lorenzi-Filho, G. and Lage L.V. (2006) Sleep Quality in Patients with Fibromyalgia Using the Pittsburgh Sleep Quality Index. The Journal of Rheumatology, 33, 1863-1865.

[6] Wolfe, F., CLauw D.J., Fitzcharles M.A., Goldenberg D.L., Katz R.S. and Mease P. (2010) The American College of Rhumatology: Preliminary Diagnostic Criteria for Fibromyalgia and Measurement of Symptom Severity. Arthritis Care \& Research, 62, 600-610. https://doi.org/10.1002/acr.20140

[7] Tan, A.C., Jaaniste, T. and Champion, D. (2019) Chronic Widespread Pain and Fibromyalgia Syndrome: Life-Course Risk Markers in Young People. Pain Research \& Management, 2019, Article ID: 6584753. https://doi.org/10.1155/2019/6584753

[8] Maese, P., Arnold, L.M., Choy, E.H., Clauw, D.J., Crofford, L.J., Glass, J.M., et al. (2009) Fibromyalgia Syndrome Module at OMERACT 9: Domain Construct. The Journal of Rheumatology, 36, 229-231. https://doi.org/10.3899/jrheum.090367

[9] Laroche, F. (2009) Actualités sur la fibromyalgie. Revue du Rhumatisme, 76, 529-536. https://doi.org/10.1016/j.rhum.2009.02.001

[10] Veale, D., Kavanagh, G., Fielding, J.F. and Fitzgerald, O. (1991) Prymary Fibromyalgia and the Irritable Bowel Syndrome Different Expressions of a Common Pathologenetic Process. Rheumatology, 30, 220-222.

https://doi.org/10.1093/rheumatology/30.3.220 
[11] Pimentel, M., Wallace, D., Hallegua, D., Chow, E., Kong, Y., Park, S. and Lin, H.C. (2004) A Link between Irritable Bowel Syndrome and Fibromyalgia May Be Ralated to Findings on Lactulose Breath Testing. Annals of the Rheumatic Diseases, 63, 42-45. https://doi.org/10.1136/ard.2003.011502

[12] Agulia, A.E., Salvi, V., Maira, G. and Rossetto, I. (2011) Fibromyalgia Syndrome and Depressive Symptoms: Comorbidity and Clinical Correlates. Journal of Affective Disorders, 128, 262-266. https://doi.org/10.1016/j.jad.2010.07.004

[13] Carneiro, G., Geronasso, A., Nascimento, M., Nascimento, L., Kletemberg, D., Veloso, G., Cunha, R., Guarita-Souza, L., Simeoni, R., Francisco, J. and Kochla, K. (2019) The Impact of Fibromyalgia on Daily Women: A Contribution to Nursing Assistants. Journal of Biomedical Science and Engineering, 12, 197-200. https://doi.org/10.4236/jbise.2019.123013

[14] Keskindag, B. and Karaaziz, M. (2017) The Association between Pain and Sleep in Fibromyalgia. Saudi Medical Journal, 38, 465-475. https://doi.org/10.15537/smj.2017.5.17864

[15] Marques, A.P., Santo, A.S.D.E., Berssaneti, A.A., Matsutani, L.A. and Yuan, S.L.K. (2017) Prevalence of Fibromyalgia: Literature Review Update. Revista Brasileira de Reumatologia (English Edition), 57, 356-363.

https://doi.org/10.1016/j.rbre.2017.01.005

[16] Halioua, B., Perrot, S. and Carole, R. (2011) Prevalence of Fibromyalgia in France: The DEFI Study. BMC Musculoskeletal Disorders, 12, Article No. 224. https://doi.org/10.1186/1471-2474-12-224

[17] Conversano, C., Ciacchini, R., Tropeano, A., Orrù, G. and Gemignani, A. (2019) Psychological and Physical Interdependence between Fibromyalgia Syndrome and Menopause: A Review of the Literature. Mediterranean Journal of Clinical Psychology, 7, 1-19.

[18] Ospina, M. and Harstall, C. (2002) Prevalence of Chronic Pain: An Over View. Health Technology Assessment Series A No. 29, Alberta Heritage Foundation for Medical Research Edmonton, Edmonton, 103-147

[19] Tu, C.-H., Lin, C.-L., Yang, S.-T., Shen, W.-C. and Chen, Y.-H. (2020) Hormonal Contraceptive Treatment May Reduce the Risk of Fibromyalgia in Women with Dysmenorrhea: A Cohort Study. Journal of Personalized Medicine, 10, Article No. 280. https://doi.org/10.3390/jpm10040280

[20] Wolfe, F., Walitt, B., Perrot, S., Rasker, J.J. and Häuser, W. (2018) Fibromyalgia Diagnosis and Biased Assessment: Sex, Prevalence and Bias. PLOS ONE, 13, e0203755. https://doi.org/10.1371/journal.pone.0203755

[21] Riley, J.L., Robinson, M.E., Wise, E.A. and Prise, D.D. (1999) A Meta-Analytic Review of Pain Perception across the Cycle. Pain, 81, 225-235. https://doi.org/10.1016/S0304-3959(98)00258-9

[22] Anderberg, U.M., Marteinsdottir, I., Theorell, T. and von Knorring, L. (2000) The Impact of Life Event in Female Patient with Fibromyalgia and Female Healthy Controls. European Psychiatry, 15, 295-301. https://doi.org/10.1016/S0924-9338(00)00397-7

[23] Yunus, M.B. (2002) Gender Differences in Fibromyalgia and Other Related Syndromes. Journal of Gender-Specific Medicine, 5, 42-47.

[24] Khoonsari, P.E., Musunri, S., Herman, S., Svensson, C.I., Tanum, L., Gordh, T. and Kultima, K. (2019) Systematic Analysis of the Cerebrospinal Fluid Proteome of Fibromyalgia Patients. Journal of Proteomics, 190, 35-43. 
https://doi.org/10.1016/j.jprot.2018.04.014

[25] Khoonsari, P.E., Ossipova, E., Lengqvist, J., Svensson, C.I., Kosek, E., Kadetoff, D., Jakobsson, P.J., Kultima, K. and Lampa, J. (2019) The Human CSF Pain Proteome. Journal of Proteomics, 190, 67-76. https://doi.org/10.1016/j.jprot.2018.05.012

[26] Neeck, G. and Riedel, W. (1994) Neuromediator and Hormonal Perturbations in Fibromyalgia Syndrome: Results of Chronic Stress? Baillière's Clinical Rheumatology, 8, 763-775. https://doi.org/10.1016/S0950-3579(05)80047-0

[27] Guter, N. (2002) Pathogenic Mechanisms of Fibromyalgia. Ageing Research Reviews, 1, 243-255. https://doi.org/10.1016/S1568-1637(01)00004-6

[28] Yunus, M.B., Dailey, J.W., Aldag, J.C., Masi, A.T. and Jobe, P.C. (1992) Plasma Tryptophan and Other Amino Acids in Primary Fibromyalgia: A Controlled Study. The Journal of Rheumatology, 19, 90-94.

[29] Moldofsky, H. and Warsh, J.J. (1978) Plasma Tryptophan and Musculoskeletal Pain in Non-Articular Rheumatism ("Fibrositis Syndrome”). Pain, 5, 65-71.

[30] Singh, L., Kaur, A., Bhatti, M.S. and Bhatti, R. (2019) Possible Molecular Mediators Involved and Mechanistic Insight into Fibromyalgia and Associated Co-Morbidities. Neurochemical Research, 44, 1517-1532. https://doi.org/10.1007/s11064-019-02805-5

[31] Chrousos, G.P. (1992) Regulation and Dysregulation of the Hypothalamic-PituitaryAdrenal Axis: The Corticotropin-Releasing Hormone Perspective. Endocrinology and Metabolism Clinics of North America, 21, 833-858. https://doi.org/10.1016/S0889-8529(18)30191-9

[32] Mastorakos, G., Pavlatou, M.G. and Mizamtsidi, M. (2006) The Hypothalamic-Pituitary-Adrenal and the Hypothalamic-Pituitary-Gonadal Axes Interplay. Pediatric Endocrinology Reviews, 3, 172-181.

[33] Mastorakos, G., Webster, E.L., Friedman, T.C. and Chrousos, G.P. (1993) Immunoreactive Corticotropin-Releasing Hormone and Its Binding Sites in the Rat Ovary. Journal of Clinique Investigation, 92, 961-968. https://doi.org/10.1172/JCI116672

[34] Mastorakos, G., Scopa, C.D., Kao, L.C., Vryonidou, A., Friedman, T.C., Kattis, D., Phenekos, C., Rabin, D. and Chrousos, G.P. (1996) Presence of Immunoreactive Corticotropin-Releasing Hormone in Human Endometrium. The Journal of Clinical Endocrinology and Metabolism, 81, 1046-1050.

https://doi.org/10.1210/jcem.81.3.8772574

[35] Magiakou, M.-A., Mastorakos, G., Rabin, D., Margioris, A.N., Dubbert, B., Calogero, A.E., Tsigos, C., Munson, P.J. and Chrousos, G.P. (1996) The Maternal Hypothalamic-Pituitary-Adrenal Axis in the Third Trimester of Human Pregnancy. Clinical Endocrinology, 44, 419-428. https://doi.org/10.1046/j.1365-2265.1996.683505.x

[36] Magiakou, M.A., Mastorakos, G., Webster, E. and Chrousos, G.P. (1997) The Hypothalamic-Pituitary-Adrenal Axis and the Female Reproductive System. Annals of the New York Academy of Sciences, 816, 42-56.

https://doi.org/10.1111/j.1749-6632.1997.tb52128.x

[37] Neeck, G. and Riedel, W. (2006) Hormonal Pertubations in Fibromyalgia Syndrome. Annals of the New York Academy of Sciences, 876, 325-339.

https://doi.org/10.1111/j.1749-6632.1999.tb07657.x

[38] Tsigos, C. and Chrousos, G.P. (1994) Physiology of the Hypothalamic-Pituitary-Adrenal Axis in Health and Dysregulation in Psychiatric and Autoimmune Disorders. Endocrinology and Metabolism Clinics of North America, 23, 451-466. https://doi.org/10.1016/S0889-8529(18)30078-1 
[39] Brooks, L., Hadi, J., Amber, K.T., Weiner, M., La Riche, C.L. and Ference, T. (2015) Assessing the Prevalence of Autoimmune, Endocrine, Gynecologic, and Psychiatric Comorbidities in an Ethnically Diverse Cohort of Female Fibromyalgia Patients: Does the Time from Hysterectomy Provide a Clue. Journal of Pain Research, 8, 561-569. https://doi.org/10.2147/JPR.S86573

[40] Albano, S.A. and Wallace, D.J. (2001) Managing Fatigue in Patients with SLE. The Journal of Musculoskeletal Medicine, 18, 149-152.

[41] Chrousos, G.P., Torpy, D.J. and Gold, P.W. (1998) Interactions between the Hypothalamic-Pituitary-Adrenal Axis and the Female Reproductive System: Clinical Implications. Annals of Internal Medecine, 129, 229-240. https://doi.org/10.7326/0003-4819-129-3-199808010-00012

[42] Roop, J.K. (2018) Hormone Imbalance-A Cause for Concern in Women. Research Journal of Life Sciences, Bioinformatics, Pharmaceuticals and Chemical, 4, 237-251.

[43] Jehan, S., Masters-Isarilov, A., Salifu, I., Zizi, F., Jean-Louis, G., Pandi-Perumal, S.R., Gupta, R., Brzezinski, A. and McFarlane, S.I. (2015) Sleep Disorders in Postmenopausal Women. Journal of Sleep Disorders \& Therapy, 4, Article No. 212.

[44] Spiegel, D., Giese-Davis, J., Taylor, C.B. and Kraemer, H. (2006) Stress Sensitivity in Metastatic Breast Cancer: Analysis of Hypothalamic-Pituitary-Adrenal Axis Function. Psychoneuroendocrinology, 31, 1231-1244. https://doi.org/10.1016/j.psyneuen.2006.09.004

[45] Taheri, S., Lin, L., Austin, D., Young, T. and Mignot, E. (2004) Short Sleep Duration Is Associated with Reduced Leptin, Elevated Ghrelin, and Increased Body Mass Index. PLoS Medecine, Article No. e62. https://doi.org/10.1371/journal.pmed.0010062

[46] Ahrens, W., Pigeot, I., Pohlabeln, H., De Henauw, S., Lissner, L., Molnár, D., et al. (2014) Prevalence of Overweight and Obesity in European Children below the Age of 10. International Journal of Obesity, 38, S99-S107. https://doi.org/10.1210/endo.137.10.8828472

[47] Calogero, A.E., Burrello, N., Negri-Cesi, P., Papale, L., Palumbo, M.A., Cianci, A., Sanfilippo, S. and D'Agata, R. (1996) Effects of Corticotropin-Releasing Hormone on Ovarian Estrogen Production In Vitro. Endocrinology, 137, 4161-4166.

[48] Ghizzoni, L., Mastorakos, G., Vottero, A., Barreca, A., Furlini, M., Cesarone, A., Ferrari, B., Chrousos, G.P. and Bernasconi, S. (1997) Corticotropin-Releasing Hormone (CRH) Inhibits Steroid Biosynthesis by Cultured Human Granulosa-Lutein Cells in a CRH and Interleukin-1 Receptor-Mediated Fashion. Endocrinology, 138, 4806-4811. https://doi.org/10.1210/endo.138.11.5474

[49] Fernandez, H., Gervaise, A. and de Trayc, R. (2002) Fibromes utérins. EMC-Gynécologie, 1, 1-11.

[50] Rongières, C. (1999) Recommandations pour la pratique clinique. Prise en charge des fibromes. Epidémiologie du fibrome utérin: Facteurs de risques et fréquence. Impact en santé publique. Journal de Gynécologie Obstétrique et Biologie de la Reproduction, 28, 701-706.

[51] Flynn, M., Jamison, M., Datta, S. and Myers, E. (2006) Health Care's Resource Use for Uterine Fibroid Tumors in the United States. American Journal of Obstetrics \& Gynecology, 195, 955-964. https://doi.org/10.1016/j.ajog.2006.02.020

[52] Christin-Maitre, S. and Wirthner, D. (1999) Fibromes utérins: Classification et physiopathologie. Journal de gynécologie obstétrique et de biologie de la reproduction, 28, 707-714.

[53] Loverro, G., Vicino, M., Lorusso, F., Vimercati, A., Greco, P. and Selvaggi, L. (2001) Polycystic Ovary Syndrome: Relationship between Insulin Sensitivity, Sex Hormone Levels and Ovarian Stromal Blood Flow. Gynecological Endocrinology, 15, 142-149. 
https://doi.org/10.1080/gye.15.2.142.149

[54] Azziz, R. (2004) PCOS: A Diagnostic Challenge. Reproductive BioMedicine Online, 8, 644-648. https://doi.org/10.1016/S1472-6483(10)61644-6

[55] Kondoh, Y., Uemura, T., Masahiko, I., Yokoi, N. and Hirahara, F. (1999) Classification of Polycystic Ovary Syndrome into Three Types According to Response to $\mathrm{Hu}$ man Corticotropin-Releasing Hormone. Fertility and Sterility, 72, 15-20. https://doi.org/10.1016/S0015-0282(99)00195-8

[56] Alpin, J.D. (1991) Implantation, Trophoblast Differntiation and Haemochorial Placentation: Mechanistic Evidence In Vivo and Vitro. Journal of Cell Science, 99, 681-692. https://doi.org/10.1242/jcs.99.4.681

[57] Makrigiannakis, A., Zoumakis, E., Kalantaridou, S., Coutifaris, C., Margioris, A.N., Coukos, G., et al. (2001) Corticotropin-Releasing Hormone Promotes Blastocyst Implantation and Early Maternal Tolerance. Nature Immunology, 2, 1018-1024. https://doi.org/10.1038/ni719

[58] McLean, M., Bisits, A., Davies, J., Woods, R., Lowry, P. and Smith, R. (1995) A Placental Clock Controlling the Length of Human Pregnancy. Nature Medicine, 1, 460-463. https://doi.org/10.1038/nm0595-460 